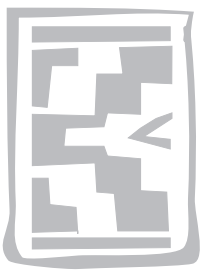

\title{
Effect of diminazene block treatment on live redwater vaccine reactions
}

\author{
M.P. COMBRINK ${ }^{1}$ and P.C. TROSKIE \\ Parasitology Division, Onderstepoort Veterinary Institute \\ Private Bag X05, Onderstepoort, 0110 South Africa
}

\begin{abstract}
COMBRINK, M.P. \& TROSKIE, P.C. 2004. Effect of diminazene block treatment on live redwater vaccine reactions. Onderstepoort Journal of Veterinary Research, 71:113-117

One third of the manufacturer's prescribed dose of diminazene has long been used to block treat the South African unfrozen Babesia bigemina and Babesia bovis (redwater) vaccine reactions, with no known adverse effects. It is known that the inhibitory effect of antibabesial drugs is more pronounced in animals inoculated with the frozen vaccine than those with the unfrozen vaccine. Reports of vaccine failures in some animals in which diminazene was used for block treatment of the reactions following inoculation with frozen South African redwater vaccine led us to reinvestigate the required waiting period before treatment and the reduced dose necessary for successful treatment and development of immunity. Results from febrile reactions in cattle following vaccination indicated day 7 as the optimal day for administering block treatment. Treatment of $B$. bigemina vaccine reactions in cattle on day 7 at a level of $0.35 \mathrm{mg} / \mathrm{kg}(1 / 10$ fraction of the normal dose) diminazene killed all the parasites while $B$. bovis vaccine parasites survived treatment using diminazene at levels between 0.35 $\mathrm{mg} / \mathrm{kg}$ and $1.16 \mathrm{mg} / \mathrm{kg}$. However, various other factors, such as the degree of natural resistance of different cattle breeds and individual animals, the accuracy of diminazene content according to the manufacturer's label claim and the accuracy of the drug dose administered, all influence the successful immunization of animals. Consequently block treating of Babesia vaccines with diminazene on day 7 after vaccination is not recommended.
\end{abstract}

Keywords: Babesia bigemina, Babesia bovis, babesiosis, diminazene, live redwater vaccine

\section{INTRODUCTION}

The South African bivalent unfrozen redwater vaccine containing Babesia bigemina and Babesia bovis infected blood was sold until April 1998, when it was finally discontinued and replaced by the two frozen monovalent African (Babesia bigemina) and Asiatic (Babesia bovis) redwater vaccines.

Diminazene aceturate has been shown to be highly effective against $B$. bigemina at levels from 0.5 to

\footnotetext{
1 E-mail: mike@moon.ovi.ac.za

Accepted for publication 10 November 2003-Editor
}

$3.0 \mathrm{mg} / \mathrm{kg}$ (Kutler 1981). Therefore, a third (1.16 $\mathrm{mg} / \mathrm{kg}$ ) of the prescribed dose of the antibabesial drug diminazene has long been used to block-treat the unfrozen redwater vaccine reactions on day 7 with no known adverse effects to the organisms or to the development of protective immunity in the animal (De Waal 1996). The attenuated organisms used in the unfrozen redwater vaccine are susceptible for longer periods to the residual effects of diminazene and imidocarb dipropionate than the virulent field strains (F.T. Potgieter \& M.P. Combrink, unpublished observations 1982). In addition, the inhibitory effect, especially of imidocarb, is more pronounced in reactions following the administra- 
tion of the frozen South African B. bovis and $B$. bigemina vaccines than in those of the unfrozen vaccine (Combrink, Troskie \& De Waal 2002). In a recent study on 19 different brands of diminazene obtained from 11 African countries, it was found that approximately one out of every three samples tested fell outside the $\pm 10 \%$ tolerance limit of the manufacturer's label claim on the content of diminazene aceturate (Tettey, Atsriku, Chizyuka \& Slingenberg 2002).

Based on these findings and reports of vaccine failures in some animals in which diminazene was used for the block treatment of vaccine reactions (Combrink, personal observations 2001), it was decided to reinvestigate the duration of the interval between vaccination and treatment as well as the optimum dosage rate of diminazene necessary for successful treatment and development of immunity.

\section{MATERIALS AND METHODS}

\section{Animals}

Fifty-four fully susceptible 6- to 12-month-old intact Ayershire and Friesian cattle, procured as calves and raised in quarantine stables, were used in a trial to determine the waiting period required before administering diminazene after inoculation with the frozen vaccine. The animals were selected randomly and were divided into two groups (Table 1).

The efficacy of using reduced dosage rates of diminazene to treat frozen vaccine reactions was determined in eight fully susceptible 20- to 30-month-old splenectomized Hereford cattle born and bred in the stables of the Parasitology Division of the Onderstepoort Veterinary Institute. They were divided into four groups of two animals each (Table 2).

The effect of using reduced dosage levels of diminazene to block-treat frozen vaccine reactions was assessed using twenty-four fully susceptible 12- to 22-month-old intact Hereford and Friesian cattle born and bred in the stables of the Parasitology Division. The animals were placed into six experimental, two treated and two untreated control groups (Table 3).

All the animals were housed under tick-free conditions before and for the duration of the experiments.

\section{Drug administration, vaccination and heterologous challenge}

Accurately determined reduced doses of commercially available diminazene (Berenil RTU, Intervet
SA) were administered to those experimental animals indicated in Tables 2 and 3.

The frozen Babesia vaccines that were used contained the B. bovis South African "S" strain (De Vos 1978; Callow, Mellors \& McGreggor 1979) and the $B$. bigemina Australian "G" strain (Dalgleish, Callow, Mellors \& McGreggor 1981; De Vos, Combrink \& Bessenger 1982). The vaccines were thawed by placing them directly from liquid nitrogen storage onto melting ice in which they were kept for $4 \mathrm{~h}$ before intramuscular inoculation of $1 \mathrm{~m} \ell$ volumes into those experimental animals indicated in Tables 1, 2 and 3.

The frozen heterologous blood stabilates that were used to challenge the cattle were the $B$. bovis South African "F" strain ( De Vos 1978) and the B. bigemina South African unmodified "P" strain (De Vos et al. 1982). At 120 days post vaccination, these frozen stabilates were thawed directly in a container with water at $37^{\circ} \mathrm{C}$ and administered intramuscularly, in quantities that contained $5 \times 10^{7}$ parasites before freezing, into those animals indicated in Table 3.

\section{Monitoring redwater reactions}

Rectal temperatures, haematocrit levels and blood smears were monitored daily (De Waal \& Potgieter 1987). Antibodies against Babesia were determined in sera collected before and 30 days after vaccination or challenge, using the indirect fluorescent antibody test technique (Gray \& De Vos 1981).

\section{Evaluation of infectivity and reactions}

The criteria used to evaluate successful infectivity were either a positive blood smear diagnosis or positive seroconversion following vaccination or challenge. Evaluation of the vaccine or challenge reactions was based on a total reaction index score determined during the reaction period for each animal, by adding one point scored for every $1 \%$ parasitaemia, $1 \%$ decline in packed red blood cell volume (De Vos 1978) and $1{ }^{\circ} \mathrm{C}$ in total temperature rise above the mean pre-inoculation normal temperature of the animal (Combrink, De Waal \& Troskie 1997). Five points were scored for other clinical signs and ten points for every antibabesial drug treatment, blood transfusion and death.

The unpaired $t$-test was used to determine whether results obtained for the mean total reaction indexes of the vaccinated and challenged groups differed significantly $(P<0.05)$. 


\section{RESULTS AND DISCUSSION}

\section{Start of vaccine temperature reactions}

Results from febrile responses in 12 of the $28 \mathrm{~B}$. bigemina vaccinated animals of group 1 (Table 1), indicated day 7 as the mean starting time of temperature rise $\geq 39.5^{\circ} \mathrm{C}$. As some of the temperature reactions to $B$. bovis in group 2 animals began as early as day 6 and due to the fact that the two vaccines are genarally inoculated simultaneously, it was decided that the waiting period required before block treating of vaccine reactions should remain at 7 days. None of the animals in the two groups showed any clinical signs of disease.

\section{Treatment efficacy of reduced diminazene doses}

Results obtained in this study using 0.5 and 0.35 $\mathrm{mg} / \mathrm{kg}$ doses of diminazene to treat $B$. bigemina and $B$. bovis vaccine reactions in the splenectomized cattle proved to be quite effective at parasitaemia levels higher than those which normally prevail in intact animals on day 7 after vaccination. None of the animals in the four groups required any additional treatment (Table 2).

\section{Effect of block treatment on the development of immunity}

\section{Babesia bigemina}

No parasites could be demonstrated in the blood smears of the experimental animals in groups 1,2 and 3 after treatment of vaccine reactions on day 7 with $1.16,0.58$ or $0.35 \mathrm{mg} / \mathrm{kg}$ doses of diminazene and none of the animals seroconverted (Table 3 ). Attempts to detect the organisms by subinoculating $100 \mathrm{ml}$ blood from each individual animal into susceptible splenectomized animals also proved negative.

Heterologous challenge of experimental animals produced clinical disease requiring treatment in $50 \%$ of the animals. This contributed to significant differences between challenge and vaccination reaction indices, indicating no or inadequate immune response to the killed vaccine parasites. Both the vaccinated untreated control animals (group 4) were positive on blood smear examination and serology, and showed no difference between mean challenge and vaccination reaction index results.

None of the heterologous strain-infected animals of the unvaccinated treated control group 5 developed clinical signs that required treatment and the resulting mean reaction index also showed no significant differences when compared to those obtained for the vaccinated control and experimental groups. Nevertheless, all other results clearly indicate that block treatment with diminazene on day 7 of the $B$. bigemina vaccine reaction cannot be recommended.

\section{Babesia bovis}

Parasites could still be demonstrated in the blood smears of all of the experimental animals in groups

TABLE 1 Start of temperature reactions in cattle vaccinated with the live frozen Babesia bigemina and Babesia bovis blood vaccines

\begin{tabular}{|l|l|l|l|l|l|}
\hline Vaccine & $\begin{array}{l}\text { Group } \\
\text { no. }\end{array}$ & $\begin{array}{l}\text { No. of } \\
\text { animals }\end{array}$ & $\begin{array}{l}\text { No. of animals with } \\
\text { blood smear positive }\end{array}$ & $\begin{array}{l}\text { No. of animals } \\
\text { showing temperature } \\
\text { reactions } \geq 39,5^{\circ} \mathrm{C}\end{array}$ & $\begin{array}{l}\text { Mean start time of temp- } \\
\text { erature reactions } \geq 39,5^{\circ} \mathrm{C} \\
\text { (day } \pm \text { sd) }\end{array}$ \\
\hline $\begin{array}{l}\text { Babesia bigemina } \\
\text { Babesia bovis }\end{array}$ & 1 & 28 & $28 / 28$ & $12 / 28$ & $7.08 \pm 3.26$ \\
$11 / 26$ & $26 / 26$ & 26 & $10.55 \pm 4.87$ \\
\hline
\end{tabular}

TABLE 2 Efficacy of 0.50 and $0.35 \mathrm{mg} / \mathrm{kg}$ diminazene as treatment dose of Babesia bigemina and Babesia bovis frozen vaccine reactions in splenectomized cattle

\begin{tabular}{|l|l|l|l|l|l|}
\hline Vaccine & $\begin{array}{l}\text { Group } \\
\text { No. }\end{array}$ & $\begin{array}{l}\text { No. of } \\
\text { animals }\end{array}$ & $\begin{array}{l}\text { Diminazene dosage } \\
\mathrm{mg} / \mathrm{kg} \text { (fraction of } \\
\text { normal dose) }\end{array}$ & $\begin{array}{l}\text { Mean parasitaemia } \\
\text { at treatment } \\
(\% \pm \mathrm{sd})\end{array}$ & $\begin{array}{l}\text { Recovered animals not } \\
\text { requiring additional } \\
\text { treatment }\end{array}$ \\
\hline Babesia bigemina & 1 & 2 & $\begin{array}{l}0.50(1 / 7) \\
0.35(1 / 10)\end{array}$ & $\begin{array}{l}1.6 \pm 1.13 \\
0.8 \pm 0.14\end{array}$ & $2 / 2$ \\
Babesia bovis & 2 & 2 & $0.50(1 / 7)$ & $3.2 \pm 3.11$ \\
& 3 & 2 & $0.35(1 / 10)$ & $0.9 \pm 0.14$ & $2 / 2$ \\
& 4 & 2 & &
\end{tabular}




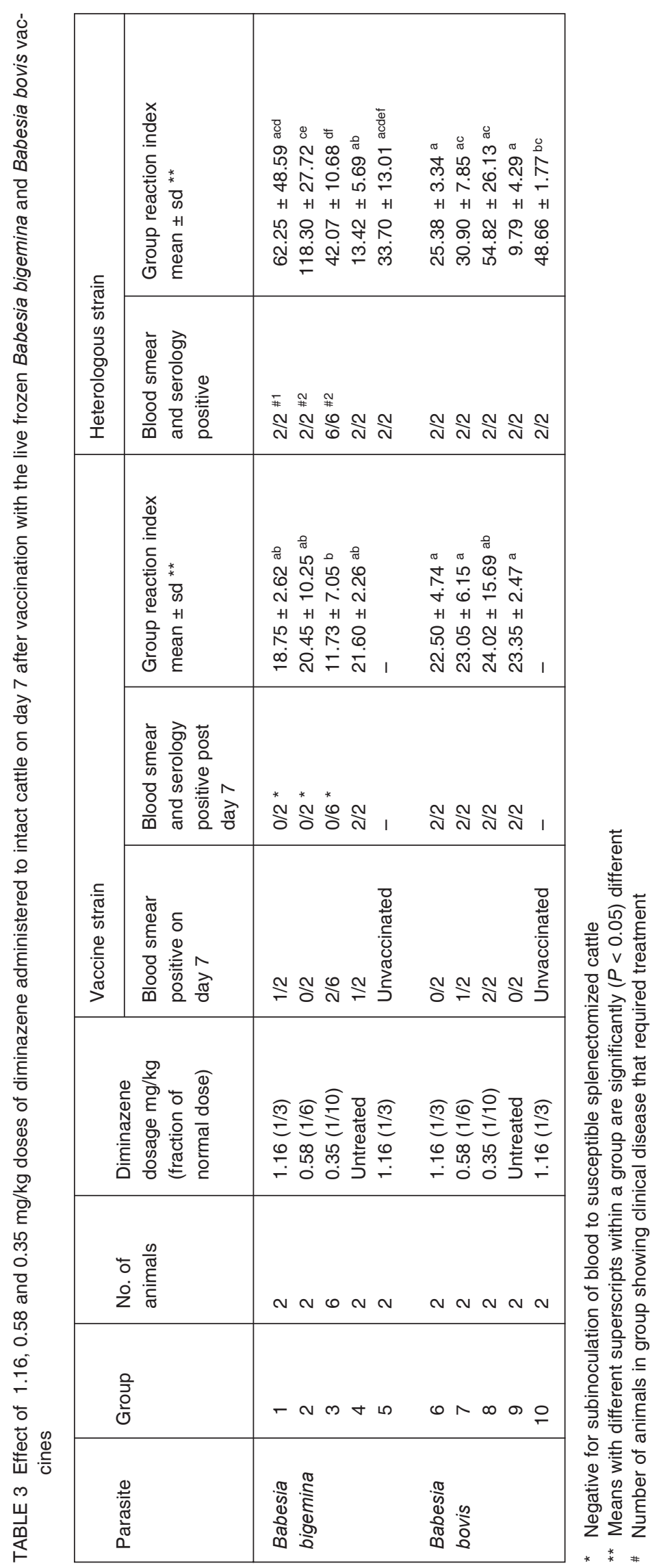


6, 7 and 8 after treatment of vaccine reactions on day 7 with $1.16,0.58$ or $0.35 \mathrm{mg} / \mathrm{kg}$ doses of diminazene and all seroconverted (Table 3). None of these, nor the animals in control group 9 required any treatment during the heterologous challenge reaction and there were no significant differences to be found between the respective challenge and vaccination reaction index results, indicating adequate protection. However, various factors, such as the degree of natural resistance of different cattle breeds and individual animals to Babesia parasites, the infectivity of frozen vaccine being less predictable than that of unfrozen vaccine (due to the death of parasites during freezing and thawing), different procedures of vaccine administration, the accuracy of diminazene content according manufacturer's label claim and the accuracy of the drug dose administered, all influence the successful immunization of animals. Consequently the block treating of $B$. bovis on day 7 of the vaccine reaction is also not recommended.

\section{REFERENCES}

CALLOW, L.L., MELLORS, L.T. \& McGREGGOR, W. 1979 Reduction in virulence of Babesia bovis due to rapid passage in splenectomized cattle. International Journal for Parasitology, 9:333-338.

COMBRINK, M.P., DE WAAL, D.T. \& TROSKIE, P.C. 1997. Evaluation of a $3 \mathrm{ml}$ heartwater (cowdriosis) infective blood vaccine dose. Onderstepoort Journal of Veterinary Research, 64:309-311.

COMBRINK, M.P., TROSKIE, P.C. \& DE WAAL, D.T. 2002. Residual effect of antibabesial drugs on the live redwater blood vaccines. Annals of the New York Acadamy of Sciences, 969:169-173.

DALGLIESH, R.J., CALLOW, L.L., MELLORS, L.T. \& McGREGGOR, W. 1981. Development of a highly infective Babesia bigemina vaccine of reduced virulence. Australian Veterinary Journal, 57:8-11.

DE VOS, A.J. 1978. Immunogenicity and pathogenicity of three South African strains of Babesia bovis in Bos indicus cattle. Onderstepoort Journal of Veterinary Research, 45:19-124.

DE VOS, A.J., COMBRINK, M.P. \& BESSENGER, R. 1982. Babesia bigemina vaccine: Comparison of the efficacy and safety of Australian and South African strains under experimental conditions in South Africa. Onderstepoort Journal of Veterinary Research, 49:155-158.

DE WAAL, D.T. \& POTGIETER, F.T. 1987. The transstadial transmission of Babesia caballi by Rhipicephalus evertsi evertsi. Onderstepoort Journal of Veterinary Research, 54: 655-656.

DE WAAL, D.T. 1996. Vaccination against babesiosis. Acta Parasitologica Turcica, 20 (supplement 1): 487-500.

GRAY, S.J. \& DE VOS, A.J. 1981. Studies on a bovine Babesia transmitted by Hyalomma marginatum rufipes Koch, 1844. Onderstepoort Journal of Veterinary Research, 48:215-223.

KUTLER, K.L. 1981. Chemotherapy of babesioses: A review, in Babesioses, edited by M. Ristic \& J.P. Kreier. New York: Academic press.

TETTEY, J., ATSRIKU, C., CHIZYUKA, G. \& SLINGENBERG, J. 2002. Non-conformance of diminazene preparations to manufacturer's label claims: an extra factor in the development of parasite resistance. ICPTV Newsletter, 5:24-25. 